\title{
Robotic surgery in a 12-year-old girl to achieve Cholecystectomy and total Splenectomy indicated for complications of hereditary spherocytosis: Case report
}

\section{TOBIE ERIC NTSOBE}

First Affiliated Hospital of Gannan Medical College: First Affiliated Hospital of Gannan Medical University https://orcid.org/0000-0002-6520-865X

\section{PENG WEI}

First Affiliated Hospital of Gannan Medical College: First Affiliated Hospital of Gannan Medical University

\section{LIU HAIJIN ( $\sim$ liuhaji@163.com )}

First Affiliated Hospital of Gannan Medical College: First Affiliated Hospital of Gannan Medical University

\section{CHEN FENG}

First Affiliated Hospital of Gannan Medical College: First Affiliated Hospital of Gannan Medical University

\section{HUANG HAIJIN}

First Affiliated Hospital of Gannan Medical College: First Affiliated Hospital of Gannan Medical University

\section{Case Report}

Keywords: Robotic surgery, hereditary spherocytosis, hemolytic anemia, cholecystectomy, splenectomy.

Posted Date: January 28th, 2022

DOI: https://doi.org/10.21203/rs.3.rs-1301025/v1

License: (c) (i) This work is licensed under a Creative Commons Attribution 4.0 International License. Read Full License 


\section{Abstract}

AlM: The application of robotic-assisted laparoscopy in pediatric surgery.

\section{MATERIALS AND METHOD:}

We used robotic-assisted laparoscopy to perform cholecystectomy and total splenectomy in a 12-year-old girl suffering from complications of chronic anemia due to hereditary spherocytosis. This report has been approved by our hospital Ethical Committee and we got a consent statement from her mother. Patient confidentiality has been respected and the intention of this work is mainly for scientific consideration.

RESULTS: We successfully removed the gallbladder and spleen with accessories using a robotic system. This intervention was safe and less risky for our patient. She improved rapidly and has been discharged after 11 days. The total length of hospital stay was 25 days. The first post-operative visit has been planned after 3 weeks.

CONCLUSION: Robotic-assisted laparoscopy is giving another issue to perform major surgeries in children. Such surgeries have since been considered more invasive with conventional laparoscopy.

\section{Introduction}

Hereditary spherocytosis is recognized to be a rare genetic disease that causes hemolytic anemia due to congenital defects of red blood cells membrane. The diagnosis is based on increasing blood spherocytes cells ${ }^{[1]}$. Spherical red blood cells that had lost their deformability will be destroyed by the spleen when passing through splenic capillaries. The hyper-destruction of red blood cells leads to hemolytic anemia [2] At the same time, red blood cells lysis releases a large quantity of bilirubin that increases splenic activity and stimulates compensatory hyperplasia and secondary liver enlargement ${ }^{[3]}$. Common complications of hereditary spherocytosis reported in the literature are bilirubin stones, anemia, hepatomegaly, splenomegaly, chronic jaundice, reticulocytosis, fatigue, and abdominal discomfort ${ }^{[4]}$. Bilirubin gallstones are the most recurrent with an incidence of about $40-50 \%$ and occur usually at the age of 10-30 years ${ }^{[5]}$. The treatment of those complications includes cholecystectomy and total splenectomy. We chose to achieve this surgery using DA Vinci robotic system.

\section{Results And Discussion}

A 12-year-old girl was admitted to our department one month ago due to repeated pain in the right upper abdominal quadrant for 6 years that got worst 3 days ago. The patient has a family history of hereditary spherocytosis and hemolytic anemia. Her mother had undergone massive splenectomy due to spherocytosis. The genetic test report done in 2019 revealed a variant of the SPTB gene and the diagnosis of spherocytosis type 2 has since been evoked. Physical examination revealed jaundice of the skin and sclera, a mildly distended abdomen, obvious tenderness in the right upper abdomen and around the umbilicus, positive Murphy's sign, mild hepatomegaly, and splenomegaly. We assessed an Abdominal 
Enhanced CT scan that revealed, lower common bile duct stones with dilatation of intra hepatic and extrahepatic bile ducts; multiple gallbladder stones; Splenomegaly with low splenic signal, suggesting iron deposition (Figure 1A). Biological Report was: WBC: 16.06×10*9/L, HB: 71g/L, total bilirubin: 430.8 $\mu \mathrm{mol} / \mathrm{L}$, indirect bilirubin: $385.1 \mu \mathrm{mol} / \mathrm{L}$.

On admission, we considered diagnosis of Cholangio cholecystitis associated to chronic splenomegaly due to high splenic activity. Indications of ERCP, cholecystectomy and splenectomy have been discussed and adopted by our medical staff. Before intervention, the Patient received medical treatment constituted by antibiotics, hepato protectors and correction of anemia. The ERCP has been performed 5 days after admission and aimed to remove stones in the bile ducts and reduce pain. After this procedure, a control CT scan has been assessed to confirm the patency of different bile ducts (Figure 1 B). The patient underwent a robot-assisted laparoscopy 9 days following ECRP to achieve cholecystectomy and total splenectomy. The patient was in Trendelenburg position and 5 ports have been created with disposable trocars; an infra umbilical port for camera and 4 working ports as shown in Figure 2A. We proceed first to cholecystectomy according to the standard procedure of robotic surgery. The gallbladder was released from the liver; after dissection of Calot triangle; cystic artery and cystic duct were exposed and ligated with hemlock clamps before being cut with robotic knife and hemostasis was completed. Then robot's arms were adjusted to achieve splenectomy. The omentum was pulled away and splenic artery identified at the upper edge of the pancreas and ligated. We continued dissection of splenogastric, splenocolic and splenorenal ligaments that were cut progressively. The spleen was released from the diaphragm and splenic artery cut under hemostasis control. We completed resection of spleen accessories and surrounding omentum. Splenic and gallbladder beds have been checked after different resections and no bleeding was active; blood loss evaluated in the suction reservoir was $30 \mathrm{ml}$. Different resected organs have been pulled out with endo bags via a para supra pubic incision and specimen sent for histopathologic analysis (Figure 3). Results showed chronic gallbladder inflammation, vasodilatation, and congestion of splenic tissue and accessories (Figure 4). Post operative treatment consisted of antibiotics, analgesics, hepato protectors and anti-platelet aggregation drugs. Biological assessment control after operation was as follows: WBC: $7.46 \times 10 * 9 / \mathrm{L}, \mathrm{HB}: 110 \mathrm{~g} / \mathrm{L}$, total bilirubin: $37.7 \mu \mathrm{mol} / \mathrm{L}$, and indirect bilirubin: $19.1 \mu \mathrm{mol} / \mathrm{L}$. The patient recovered rapidly, the wound healing was good (Figure $2 \mathrm{~B}$ ) and she has been discharged 11 days after operation. The total length of hospital stay was 25 days and the first postoperative visit has been planned 3 weeks later.

Since the FDA approved the DA Vinci robotic surgery system in 2000 , robotic surgery has gradually been introduced in urology, general surgery, cardiothoracic surgery, gynecology, and $\mathrm{n}$ China. However, due to the scarcity of this new technology, technical difficulties and small body cavity in children, development of robotic surgery in pediatric population has been slower than in other departments. But, with advances in minimally invasive surgery, many hospitals have introduced the usage of robot in pediatric surgery. Out of the number of DA Vinci robotic system that is increasing; implementation of robotic in Pediatric surgery has been considerable in recent years ${ }^{[6]}$. Nowadays, many pediatric surgeons are already qualified for robotic operations. Since 2004, some scholars in US projected that robotic surgery in 
pediatrics is the most promising ${ }^{[7]}$. This may be due to the current hardware equipment and the characteristics of pediatric surgical diseases. Current authors recognize that robotic surgery is safe in children with a body weight of more than 15 kilograms and aged more than 2 years ${ }^{[8]}$. Our patient was 12 years old and weighed 41 kilograms, which is still widely recognized as eligible for robotic surgery. Robotic surgery is feasible to remove spleen and gallbladder at the same time. In case of an idiopathic thrombocytopenic purpura, hereditary spherocytosis or thalassemia with indications of simultaneous cholecystectomy and splenectomy, surgeons have been using laparoscopy to achieve this surgery [9-11]. Many cases of robotic surgery for multiple organ surgery have been reported in recent years. A 61-yearold woman with multifocal intraductal papillary mucinous tumor underwent simultaneous removal of the pancreas and spleen using DA Vinci robotic machine and 6 ports to achieve this surgery ${ }^{[12]}$. In addition, a 62-year-old male patient with pancreatic tail tumors and liver metastases, stomach involvement, splenic inflexion and colon compression underwent multiple organs removal with robotic system. The Surgeon performed simultaneously pancreatectomy, splenectomy, gastric sleeve resection, and cholecystectomy [13]. Recently in 2018, an Italian surgeon reported one case of a lymphoblastic auto-immune syndrome on a 52-year-old woman where he used robot to remove spleen and gallbladder at the same time ${ }^{[14]}$. Certainly, this report of simultaneous removal of the gallbladder and spleens in a child using robotic system will provide a new option for similar cases in the future. Patients with hereditary spherocytosis Complicated with symptomatic gallbladder stones and aged more than 6 years have indications of simultaneous removal of the gallbladder and spleen $[15,16]$. Laparoscopic removal of the gallbladder and spleen for treatment of hereditary spherocytosis and complications has since been reported ${ }^{[17,18]}$. Splenectomy is safe and helpful for patients with hereditary spherocytosis ${ }^{[19]}$. A few numbers of patients did not improve because of the presence of spleen accessories ${ }^{[20]}$. Our patient had an accessory spleen; thanks to the high-definition camera of the robotic system, we carefully removed this accessory in order to minimize the possibility of recurrence.

\section{Conclusion}

Hereditary spherocytosis is a rare disease in the general population and radical splenectomy has been described as the best surgical treatment. Gallstones are recurrent complications and simultaneous splenectomy and cholecystectomy have been constituted the aim of our treatment. Although the usage of robotic-assisted laparoscopy in pediatric surgery is facing some difficulties such as the lack of specific equipment for children, narrow body cavities, we realized a successful surgery and our patient got improved without complications. Robotic system has advantages to perform simultaneously multiple interventions compared to conventional laparoscopy that requires minimal and noninvasive surgery.

\section{Declarations}

\section{AUTHORS CONTRIBUTIONS AND DISCLOSURE}

Dr. Peng Wei consulted the patient, accessed investigations, and gave an indication of surgical treatment. 
Dr. Liu Haijin was the surgeon and has been assisted by Dr. Huang Haijin and Dr. Chen Feng.

Dr. Eric Tobie Ntsobe was charged to write this report.

Doctors Peng Wei, Eric Tobie NTSOBE, Liu Haijin, Huang Haijin, and Chen Feng have no conflict of interest to disclose for this report.

\section{ETHICS STATEMENT \& CONSENT}

This report has been approved by our hospital Ethical Committee and we got a consent statement from her mother.

All authors have contributed significantly and all are agreed with the content of the manuscript and we declare no conflict of interest for this work.

\section{References}

1. Peng Guangxin, Yang Wenrui, Zhao Xin,Jin Linping, Zhang Li,et al. Analysis of gene mutation characteristics in 37 cases of hereditary spherocytosis[J]. Chinese Journal of Hematology 2018, Volume 39, Issue 11, Pages 898-903 MEDLINE ISTIC PKU CSCD CA, 2018 . DOIه10.3760/cma.j.issn.02532727.2018.11.005

2. Gao Y, Zhang B, Song Y, Li G, Bao Y, et al. Diagnosis of hereditary spherocytosis and secondary hemochromatosis in a patient with jaundice[J]. Acta haematologica, 2018, 139(3): 168-170. DOI区 $10.1159 / 000486948$

3. Yang K, Ren Q, Wu Y, Zhou Y, Yin X. A Case of Hereditary Spherocytosis Caused by a Novel Homozygous Mutation in the SPTB Gene Misdiagnosed as $\beta$-Thalassemia Intermedia Due to a KLF1 Gene Mutation[J]. Hemoglobin, 2019, 43(2): 140-144. DOI囚10.1080/03630269.2019.1620764

4. Llaudet-Planas E, Vives-Corrons J L , Rizzuto V, Gómez-Ramírez P, Sevilla Navarro J,et al. Osmotic gradient ektacytometry: A valuable screening test for hereditary spherocytosis and other red blood cell membrane disorders [J]. International Journal of Laboratory Hematology, 2018. DOID10.1111/ijlh.12746

5. Tamary H, Aviner S, Freud E, Miskin H, Krasnov T, et al.High incidence of early cholelithiasis detected by ultrasonography in children and young adults with hereditary spherocytosis. J Pediatr Hematol Oncol 2003, 25(12):952-954.DOIه10.1097/00043426-200312000-00009

6.TANG S T. Robot-assisted surgery in children: current status and prospects [J]. Chinese Journal of Robotic Surgery,2021, 2(4):241-247.DOIX10.12180/j.issn.2096-7721.2021.04.00

7. Kant A J, Klein M D, Langenburg S E. Robotics in pediatric surgery: perspectives for imaging[J]. Pediatric radiology, 2004, 34(6): 454-461. D0lه10.1007/s00247-003-1130-3 
8. Esposito C, Masieri L, Castagnetti M, Pelizzo G, Escolino M. Current Status of Pediatric Robot-Assisted Surgery in Italy: Epidemiologic National Survey and Future Directions[J]. Journal of Laparoendoscopic \& Advanced Surgical Techniques, 2020. DOIه10.1089/lap.2019.0516

9. Alwabari A, Parida L, Al-Salem A H. Laparoscopic splenectomy and/or cholecystectomy for children with sickle cell disease[J]. Pediatric surgery international, 2009, 25(5): 417-421. DOIه10.1007/s00383009-2352-8

10. Choi Y , Han H, Yoon Y, Jang J, Kim S囚et al. Laparoscopic splenectomy plus cholecystectomy for treating hereditary spherocytosis combined with cholelithiasis in siblings[J]. Minim Invasive Ther Allied Technol, 2007, 16(5):317-318. DOIه10.1080/13645700701384108

11. Vecchio R, Intagliata E, Marchese S , Corte FL, Cacciola RR,et al. Laparoscopic Splenectomy Coupled with Laparoscopic Cholecystectomy[J]. JSLS: Journal of the Society of Laparoendoscopic Surgeons/Society of Laparoendoscopic Surgeons, 2014, 18(2):252-257. DOI》 $10.4293 / 108680813 \times 13693422518434$

12. Konstantinidis I T, Jutric Z, Eng O S, Warner SG, Melstrom LG, et al. Robotic total pancreatectomy with splenectomy: technique and outcomes[J]. Surgical endoscopy, 2018, 32(8): 3691-3696. DOI》 $10.1007 / \mathrm{s} 00464-017-6003-1$

13. Bhat A S, Farrugia A, Marangoni G, Ahmad J. Multivisceral robotic resection: a glimpse into the future of minimally invasive abdominal surgery[J]. BMJ Case Reports CP, 2020, 13(8): e234887. DOI区 $10.1136 /$ bcr-2020-234887

14. Ortenzi M, Ghiselli R, Baldarelli M, Kolynou A, Guerrieri M. Simultaneous splenectomy and cholecystectomy with single docking robotic platform[J]. Minerva chirurgica, 2018, 73(1): 107-109. DOI区 10.23736/S0026-4733.17.07459-4

15. Perrotta S, Gallagher P G, Mohandas N. Hereditary spherocytosis[J]. The Lancet, 2008, 372(9647): 1411-1426. DOIه10.1016/S0140-6736(08)61588-3

16. Currò G, lapichino G, Lorenzini C, Palmeri R, Cucinotta E. Laparoscopic cholecystectomy in children with chronic hemolytic anemia[J]. Surgical Endoscopy And Other Interventional Techniques, 2006, 20(2): 252-255. DOI冈10.1007/s00464-005-0318-Z

17. Cingel V, Zabojnikova L, Kurucova P, Varga I. First experience with single incision laparoscopic surgery in Slovakia: Concomitant cholecystectomy and splenectomy in an 11-year-old girl with hereditary spherocytosis[J]. Biomed Pap Med Fac Univ Palacky Olomouc Czech Repub, 2014, 158(3): 479-485. DOI区 $10.5507 /$ bp. 2013.058

18. Vecchio R, Intagliata E, Ferla F, et al. Laparoscopic splenectomy in patients with hereditary spherocytosis: report on 12 consecutive cases[J]. Updates in surgery, 2013, 65(4): 277-281. DOI区 
19. Reliene R, Mariani M, Zanella A, Reinhart WH, Lutz HU: Splenectomy prolongs in vivo survival of erythrocytes differently in spectrin/ankyrin- and band 3-deficient hereditary spherocytosis. Blood 2002, 100(6):2208-2215. DOI $810.1182 /$ blood-2002-04-1017

20. Mackenzie F A F, Elliot D H, Eastcott H H G, Bakkhan P, Mollison PL. Relapse in hereditary spherocytosis with proven splenunculus[J]. The Lancet, 1962, 279(7239): 1102-1104. DOI区 10.1016/S0140-6736(62)92084-6.

\section{Figures}

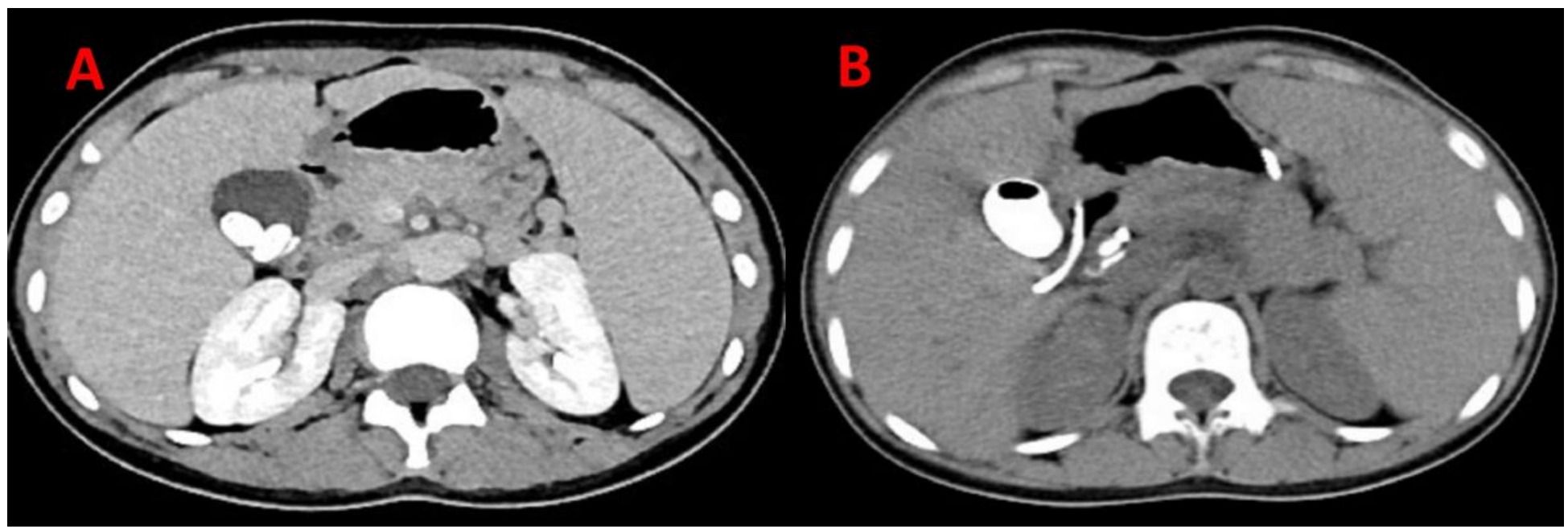

Figure 1

CTScan before and after ERCP operation

Figure 1A: Image before ERCP showed Stones in the lower part of the common bile duct with mild dilation of intra- and extra hepatic bile ducts; multiple stones in the gallbladder; splenomegaly, low splenic signal.

Figure 1B: CT scan after ERCP showed postoperative changes of stones in the lower part of the common bile duct; stones in the gallbladder; we considered retention of contrast agent in the gallbladder and bile duct. 


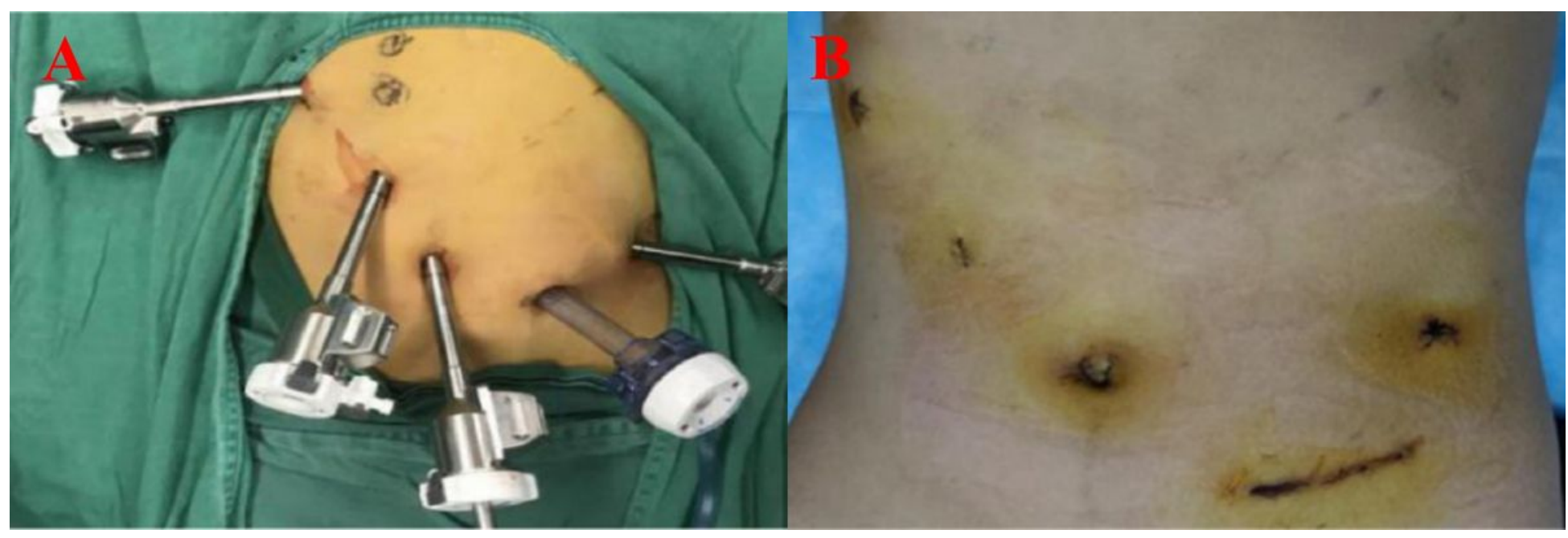

Figure 2

Port positions and wound healing

Figure 2A: Per operative port positions.

Figure 2B: postoperative wound healing (the para supra pubic incision was done to take out specimen).
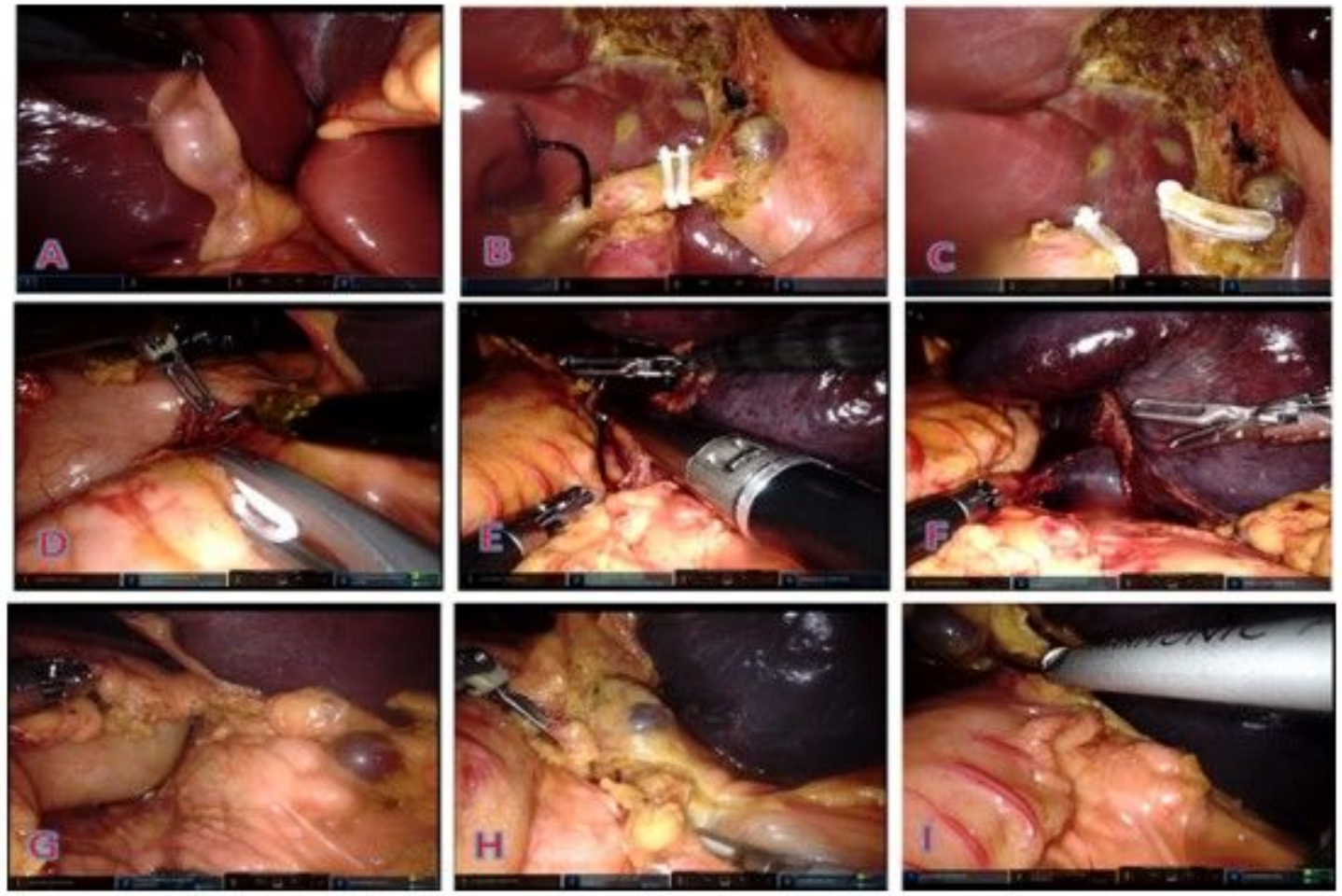

Figure 3

Pictures of surgery process

Figure 3A, 3B, 3C: Gallbladder resection 
Figure 3D, 3E, 3F: Splenectomy process

Figure 3G, 3H, 3I: Spleen accessory
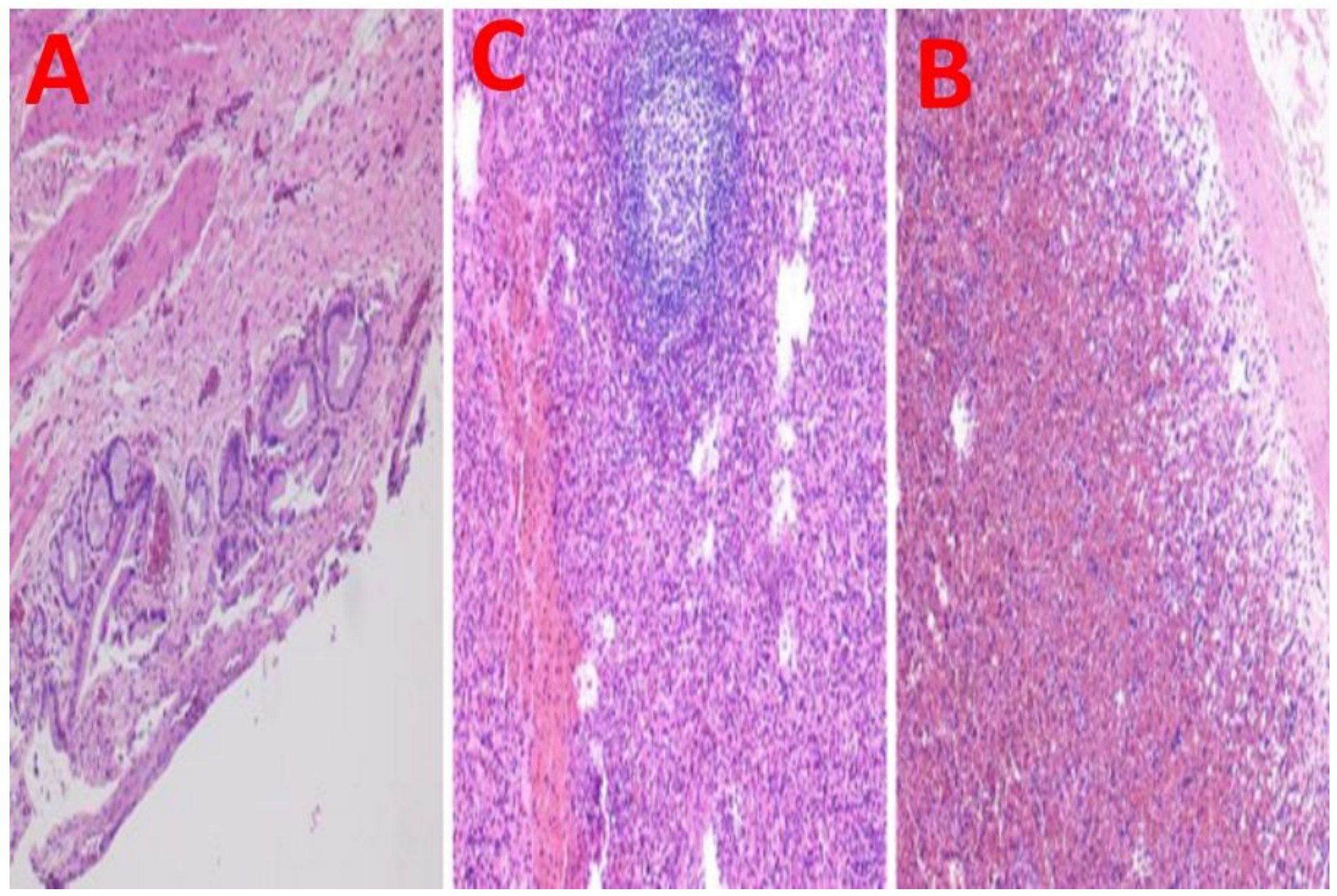

Figure 4

Histopathologic results (10x)

Figure 4A: Chronic inflammation of the gallbladder;

Figure 4B: Spleen tissue presenting vasodilatation and congestion;

Figure 4C: Spleen accessory showing also vasodilatation congestion 